\title{
CODE INADEQUACIES DISCOURAGING THE EARTHQUAKE-BASED SEISMIC ANALYSIS OF BUILDINGS
}

\author{
MARIA CRISTINA PORCU \\ Department of Mechanical, Chemical \& Materials Engineering, University of Cagliari, Italy.
}

\begin{abstract}
Despite being the more accurate method to design earthquake-resistant buildings, the non-linear dynamic analysis still remains the least used in practice. The paper shows that some code inadequacies may even contribute to ward off the designer from this kind of seismic analysis. To this purpose, non-linear analyses under different sets of spectrum-compatible earthquakes and by considering two distinct plastic-hinge models were carried out for a multistory reinforced concrete $(\mathrm{r} / \mathrm{c})$ frame designed according to the Eurocode 8 provisions. It has been shown that owing to the inadequate limits imposed to the spectrum-compatible earthquakes, the European codes of practice may lead to significant inconsistencies in the seismic design of structures through the time-history non-linear analysis.

Keywords: earthquake-resistant buildings, EC8 inadequacies, spectrum-compatible earthquakes, time-history non-linear seismic analysis.
\end{abstract}

\section{INTRODUCTION}

The seismic design philosophy typically requires that buildings may withstand events of moderate severity deforming in the elastic range, without suffering any irreversible structural damage. Conversely, during strong earthquakes structures are required to behave in a dissipative ductile way, even getting damaged severely but without collapsing. These achievements have to be reached regardless to which type of code-based analysis (linear or non-linear) is chosen. If a linear analysis is performed, in fact, a reduced response spectrum can be adopted to design the structure so as it can withstand moderate earthquakes in the elastic range, while compliance with the detailed code provisions (local ductility and strength hierarchy rules) ensure that the plastic deformation capacity of the system can satisfy the demand under stronger earthquakes. If a non-linear analysis is carried out instead, the elastic and postelastic behaviour of the structure can be straight monitored. Both a non-linear static analysis (often referred to as 'pushover') and a non-linear time-history analysis (NLTHA) are allowed by codes. The latter is expected to be the more powerful since it obtains the deformation time-history of the system through a numerical integration of the differential equations of motion under the considered earthquake.

Despite its indubitable potentials, the NLTHA is still the least applied method of seismic analysis. This may be due to the difficulties that even an experienced designer has to overcome when (i) modelling the non-linear behaviour of the system, (ii) defining the suite of spectrum-compatible earthquakes, (iii) carrying out the numerical calculations and even (iv) interpreting the results and choosing the requirements to be met. To help the designer, some codes of practice, i.e. FEMA-356 [1] and ATC-40 [2], give default properties for r/c plastic hinges, which are implemented by finite element structural programs such as SAP2000 [3]. User-friendly software tools, as for instance REXEL [4], are also available to obtain code-based selections of accelerograms.

Nevertheless, the NLTHA is still not widely adopted by practitioners and even the scientific community is sceptical about the adoption of this kind of analysis in the design practice 
due to the risks that its inexpert use may involve. A warning against these possible risks was given for instance in Ref. [5], where some of the difficulties that the non-linear dynamic analysis of reinforced concrete buildings may involve were put in evidence. In the same paper the likely dependence of the results of a NLTHA on the chosen structural model (fibre discretization model or plastic-hinge model) and on the adopted computer program (SAP2000 or SeismoStruct) were also highlighted.

With the aim to help make the non-linear dynamic analysis less difficult for the designer, the present paper further investigated on the reasons of its unattractiveness. To this end, a three-story reinforced concrete $(\mathrm{r} / \mathrm{c})$ frame was considered and assumed to be built in a high-seismicity Italian area. The frame was preliminarily designed through the modal response spectrum analysis (MRSA) according to Eurocode 8 (EC8) [6], so as to comply with all the code requirements ensuring adequate local ductility and strength hierarchy rules. In a second stage, the same building was spatially modelled in SAP2000 through a lamped plasticity idealization to perform a NLTHA. Two different mechanical models of plastic hinges and four suites of seven spectrum-compatible earthquakes were considered in the numerical investigation. The difficulties to be faced up by the designer during both the modelling and the calculation phases were evidenced.

A key question raises from the present investigation: are buildings designed through the MRSA unable to withstand earthquakes compatible with the design response spectrum or rather are the earthquakes that EC8 assumes as spectrum-compatible too strong to be considered as such? Answering to this question highlights some code inadequacies, which should be overcome to allow a wider use of the NLTHA in the engineering practice.

\section{CASE STUDY}

A three-story $\mathrm{r} / \mathrm{c}$ frame, regular both in plan and in elevation, supposed to be built in a high seismicity Italian area (Messina), was considered. The frame was initially designed through a MRSA, so as to be consistent with the no-collapse and damage limitation requirements as well as with all the ductility and strength hierarchy rules provided by EC8. The assumption of a high ductility class was made. Geometrical data, materials' properties, loads at each level of the longitudinal frames and some reinforcement details are collected in Fig. 1.

The elastic and the design response spectra adopted in the present investigation are provided in Fig. 2. They are obtained by referring to the no-collapse requirement and assuming soil type B, no topographic amplification effects and a building lifetime of 50 years. The values of all the parameters defining the shape of the response spectrum are listed in Fig. 2. They were determined following the Italian standard [7] in accordance with the EC8 provisions [6; 3.2.2.2]. The spectra in Fig. 2 are relevant to the horizontal components of the earthquake, since the vertical component may be neglected in this case, according to EC8.

It should be noted that the design spectrum in Fig. 2 was obtained by reducing the elastic spectrum through the behaviour factor $q$. Such a spectrum has to be adopted when performing a MRSA. On the contrary, the elastic (unreduced) spectrum plotted in the same figure should be considered when defining the suite of spectrum-compatible earthquakes to be used in the NLTHA.

\section{PERFORMING THE NLTHA ACCORDING TO EC8}

The $\mathrm{r} / \mathrm{c}$ frame illustrated in Fig. 1 was designed through a MRSA with reference to the design spectrum given in Fig. 2 and to all the detailing rules provided by EC8. In accordance with the code design philosophy this frame is expected to be able to withstand any earthquake 


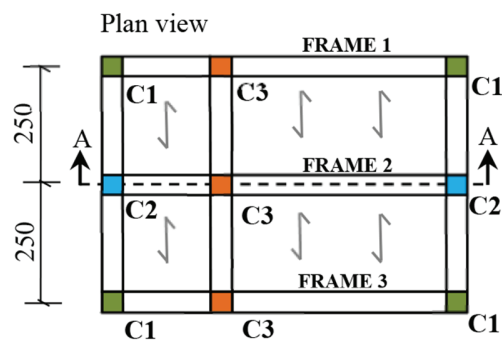

Elevation view (A-A)

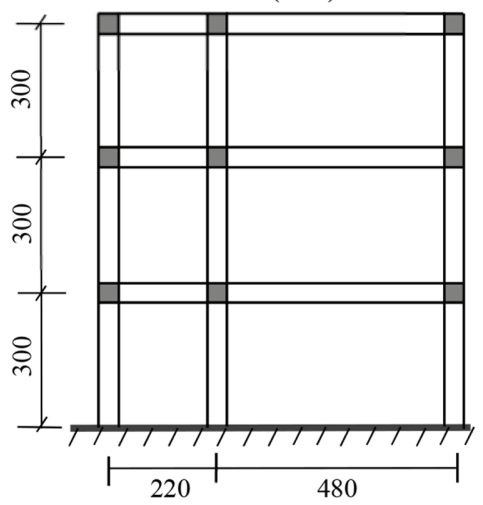

\begin{tabular}{|c|c|c|c|}
\hline \multicolumn{5}{|c|}{ Frame 2 } \\
\hline Load $[\mathrm{kN} / \mathrm{m}]$ & Level 1 & Level 2 & Level 3 \\
\hline Permanent G & 13.00 & 13.00 & 10.25 \\
\hline Variable-live Q & 5.00 & 5.00 & 10.00 \\
\hline \multicolumn{4}{|c|}{ Frames 1 and 3 } \\
\hline Load $[\mathrm{kN} / \mathrm{m}]$ & Level 1 & Level 2 & Level 3 \\
\hline Permanent G & 7.00 & 7.00 & 5.125 \\
\hline Variable-live Q & 2.50 & 2.50 & 5.00 \\
\hline
\end{tabular}

Typical beam longitudinal reinforcement details

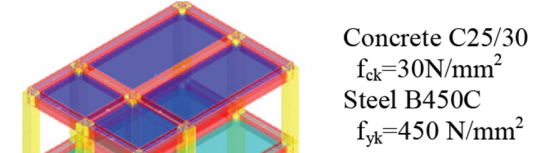

Typical column stirrup details
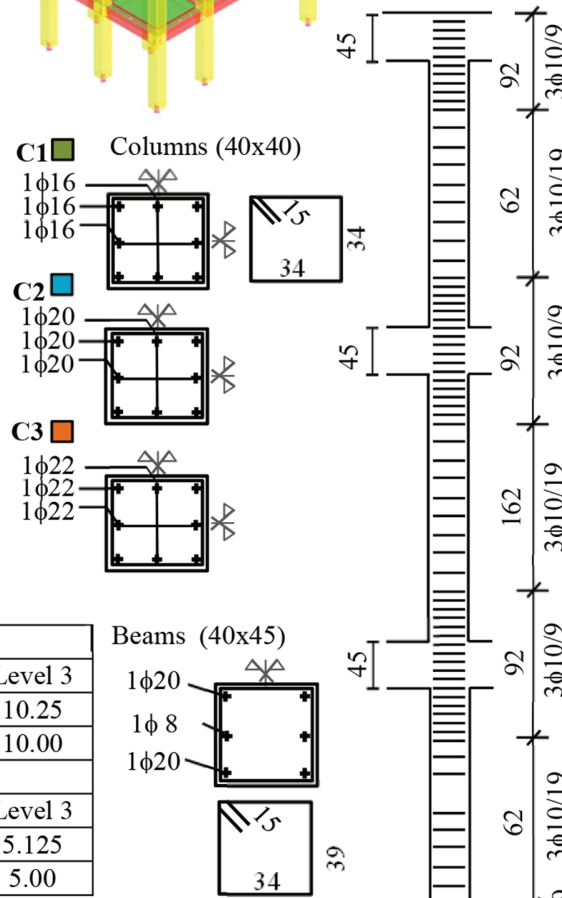
光
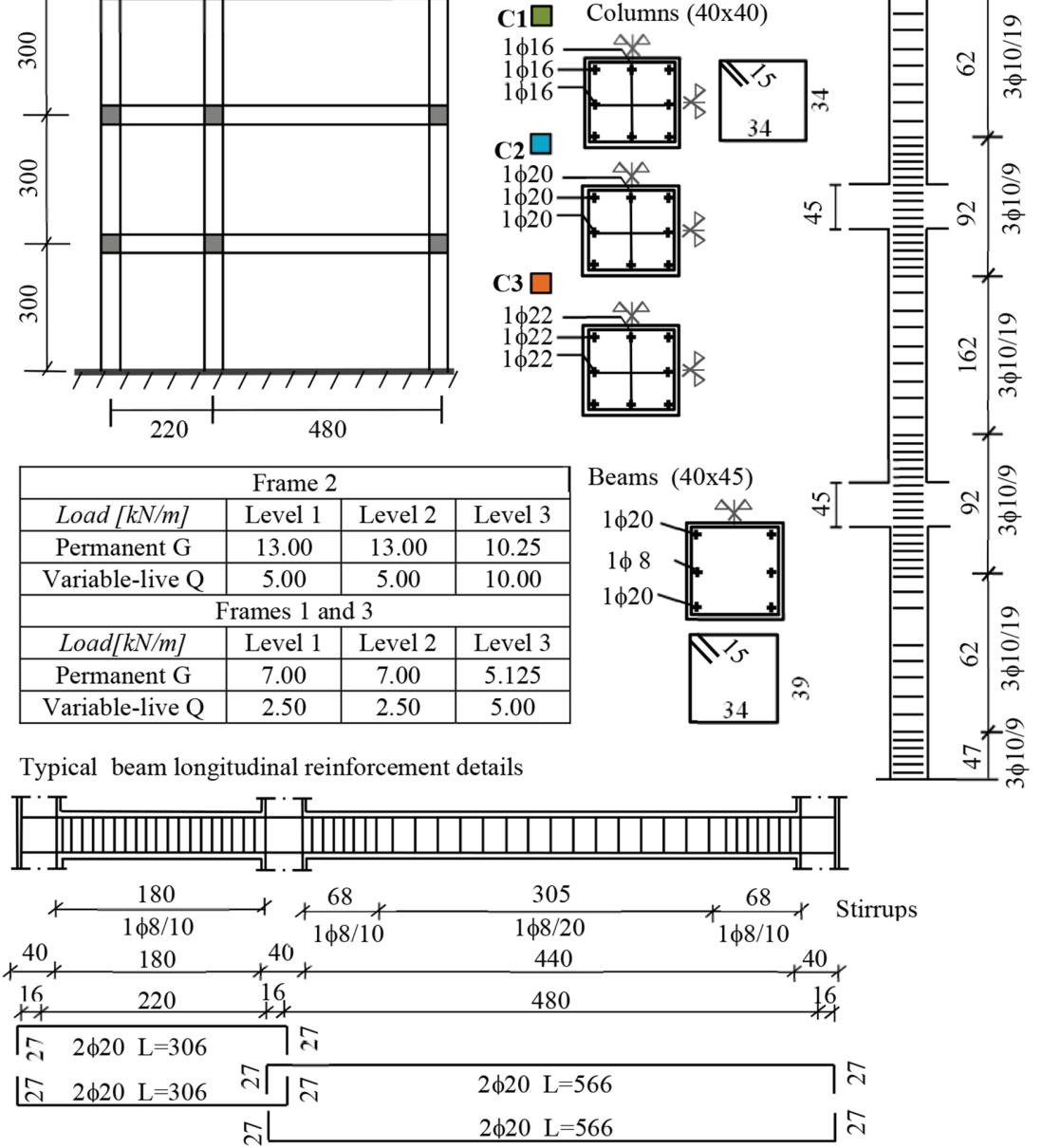

Figure 1: The r/c three-story building considered in the study.

compatible with the elastic spectrum given in Fig. 2. The criteria that decide if an earthquake is compatible with a given spectrum are stated by codes. To check whether the building concerned was able or not to withstand earthquakes that EC8 considers spectrum-compatible, a series of non-linear analyses were performed. The steps the designer has to follow to perform a NLTHA are firstly examined. The general-purpose structural program SAP2000 [3] and the software REXEL [4] were adopted to this end. 


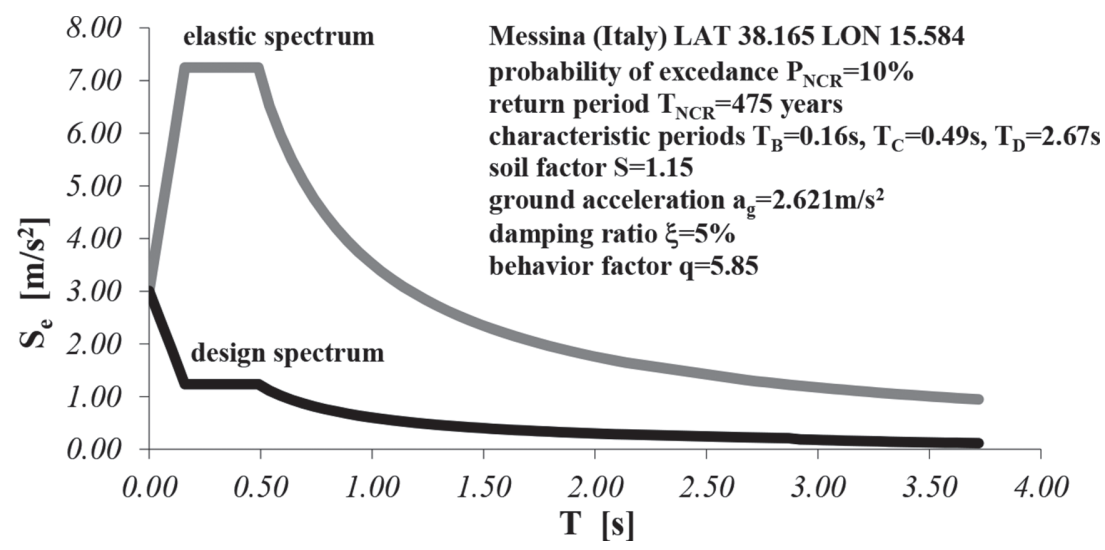

Figure 2: Elastic and design response spectra for the no-collapse requirement (horizontal component).

\subsection{Step 1: defining a suite of spectrum-compatible real accelerograms}

According to EC8 [6; 3.2.3.1.2, (4)], the designer should define in advance a suite of at least three ground acceleration time histories consistent with the reference spectrum. Some requirements, not recalled here for brevity, are provided by EC8 to achieve this goal. To find suites of recorded spectrum-compatible acceleration time histories the software REXEL [4] requires the user:

a) to define the target elastic spectrum;

b) to select an earthquake database and some related parameters;

c) to set how many records for the suite;

d) to give the spectrum matching parameters.

In the present case study, (a) the elastic spectrum of Fig. 2 was considered as target spectrum; (b) reference to the European Strong Motion Database (ESD) [8] was done by assuming a magnitude range $6 \leq M_{w} \leq 7$ and an epicentre distance $\Delta \leq 20 \mathrm{~km}$; (c) suites of seven records were considered, as required by EC8 (section 4.3.3.4.3) to consider the mean effects, rather than the maxima, on the structure. On the other hand, it can be noted that a minimum of seven records for suite is prescribed by the Italian Code [7].

As for issue (d), both an upper and a lower tolerated deviation of the average spectrum from the target spectrum should be specified. EC8 states a lower tolerance value (no more than $10 \%$ ), but does not provide any indication about the upper bound. The designer is left alone in making this choice despite the fact that it may drastically affect the final results of the analysis.

To evaluate the influence of the designer choices, two upper tolerance values, namely $30 \%$ and $20 \%$, were considered in the investigation. Since REXEL [4] allows to obtain combinations of accelerograms whose average meets the lower and upper bound tolerance being not manipulated (original records) or if linearly scaled in amplitude (scaled records), both the options of original and scaled records were set. Table 1 summarizes the main options set to obtain four suites of spectrum-compatible earthquakes to use in the investigation. 
Table 1: Suites of earthquakes compatible with the elastic spectrum of Fig. 2.

\begin{tabular}{llllllll}
\hline suite & $\begin{array}{l}\text { number of } \\
\text { histories }\end{array}$ & $\begin{array}{l}\text { earthquake } \\
\text { database }\end{array}$ & $\mathbf{M}_{\mathbf{w}}$ & $\boldsymbol{\Delta}[\mathbf{k m}]$ & $\begin{array}{l}\text { lower } \\
\text { tolerance }\end{array}$ & $\begin{array}{l}\text { upper } \\
\text { tolerance }\end{array}$ & $\begin{array}{l}\text { records } \\
\text { scaled }\end{array}$ \\
\hline Suite-1 & 7 & ESD & $6 \div 7$ & $>20$ & $10 \%$ & $30 \%$ & no \\
Suite-2 & 7 & ESD & $6 \div 7$ & $>20$ & $10 \%$ & $30 \%$ & yes \\
Suite-3 & 7 & ESD & $6 \div 7$ & $>20$ & $10 \%$ & $20 \%$ & no \\
Suite-4 & 7 & ESD & $6 \div 7$ & $>20$ & $10 \%$ & $20 \%$ & yes \\
\hline
\end{tabular}

For each case in Table 1, REXEL returned hundreds of suites of adequately qualified records, sorted for dispersion of the spectra with respect to the target spectrum. The first set of each list (relevant to the lowest dispersion), was always chosen in this study. Tables 2 and 3 give the characteristics of Suite-1 and Suite-2. For the sake of brevity, the tables with the data relevant to Suite 3 and Suite 4 are not provided herein. It can be observed that the same waveforms may appear in different suites, scaled by factors SFx and SFy (see Table 2 and Table 3). Figures 3a-d plot the spectra of the records of the four suites, together with the average, the lower and the upper tolerance spectra and the reference spectrum. Note that two acceleration histories (by the directions $\mathrm{x}$ and $\mathrm{y}$ ) are actually given for each earthquake by REXEL and, therefore, 14 record spectra are given in each diagram of Fig. 3.

Table 2: Suite-1 (original records) as obtained from REXEL.

\begin{tabular}{lllll}
\hline Waveform ID & Earthquake ID & Earthquake Name & $\mathbf{M}_{\mathbf{w}}$ & $\boldsymbol{\Delta}[\mathbf{k m}]$ \\
\hline 146 & 65 & Friuli (aftershock) & 6 & 14 \\
291 & 146 & Campano Lucano & 6.9 & 16 \\
1715 & 474 & Ano Liosia & 6 & 14 \\
230 & 108 & Montenegro (aftershock) & 6.2 & 8 \\
6334 & 2142 & South Iceland (aftershock) & 6.4 & 11 \\
199 & 93 & Montenegro & 6.9 & 16 \\
6263 & 1635 & South Iceland & 6.5 & 7 \\
\hline
\end{tabular}

Table 3: Suite-2 (scaled records) as obtained from REXEL.

\begin{tabular}{lllllll}
\hline Waveform ID & Earthquake ID & Earthquake Name & $\mathbf{M}_{\mathbf{w}}$ & $\boldsymbol{\Delta}[\mathbf{k m}]$ & $\mathbf{S F x}$ & $\mathbf{S F y}$ \\
\hline 232 & 108 & Montenegro (aftershock) & 6.2 & 20 & 5.2458 & 5.4141 \\
1713 & 474 & Ano Liosia & 6 & 18 & 2.7018 & 3.5011 \\
1711 & 474 & Ano Liosia & 6 & 20 & 3.4359 & 3.863 \\
535 & 250 & Erzincan & 6.6 & 13 & 0.77013 & 0.58428 \\
230 & 108 & Montenegro (aftershock) & 6.2 & 8 & 2.5057 & 1.1195 \\
594 & 286 & Umbria Marche & 6 & 11 & 0.57168 & 0.64726 \\
291 & 146 & Campano Lucano & 6.9 & 16 & 1.9254 & 1.7032 \\
\hline
\end{tabular}



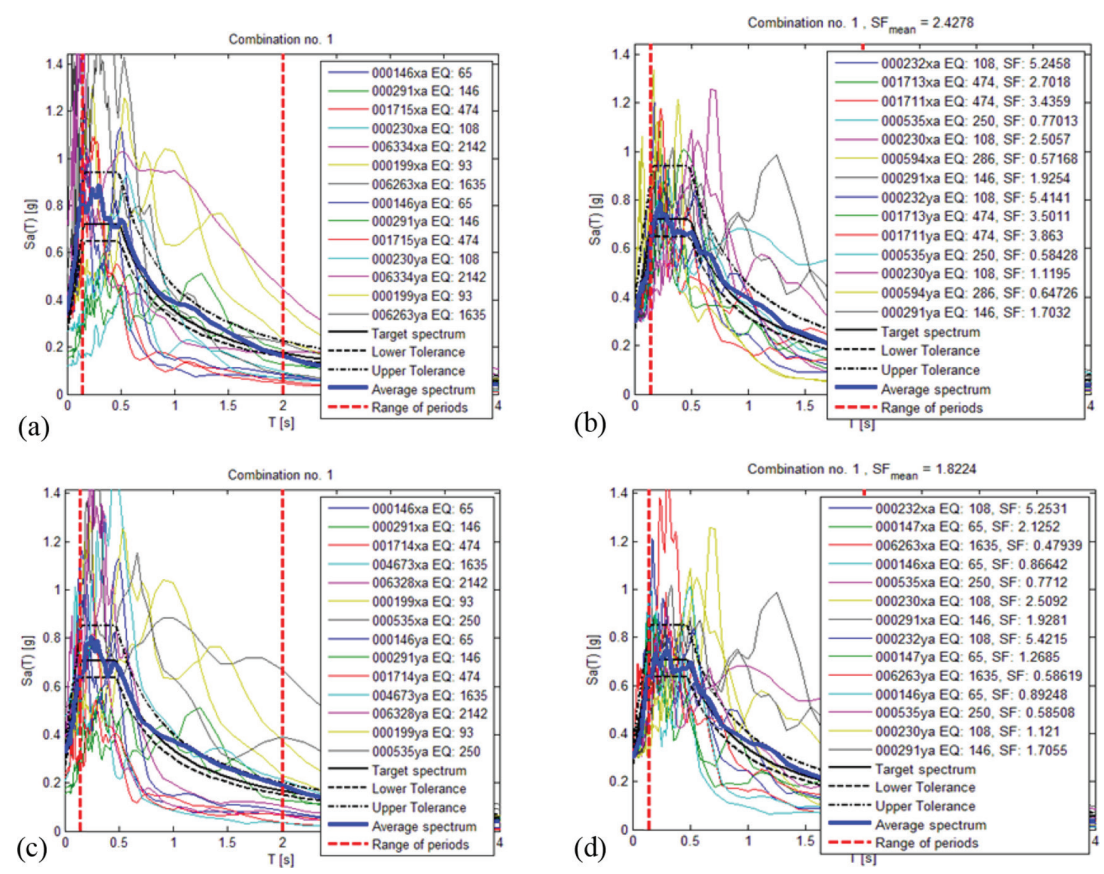

Figure 3: Response spectra for (a) Suite-1; (b) Suite-2; Suite-3; (d) Suite-4, from REXEL.

\subsection{Step 2: modelling the nonlinear behaviour of the structure}

A concentrated plasticity three-dimensional model was adopted to describe the seismic behaviour of the building in Fig. 1. Linear-elastic frame elements were adopted to model beams and columns while non-linear hinge elements were put at the end of all elements to account for the post-elastic rotation of the extreme sections. Slab masses (from loads given in Fig. 1) were assigned to beams while rigid diaphragm constraints accounted for the slab stiffening effects.

The default properties provided by SAP2000 for $\mathrm{r} / \mathrm{c}$ hinge elements are based on American codes FEMA-356 [1] and ATC-40 [2]. Although relieving modelling work considerably, default hinges of SAP2000 should be used cautiously for design guidelines different from the ones adopted in the USA, so as to prevent unreasonable results. The possible effects of the misuse of the default-hinge properties assumed by SAP2000 were also investigated in Ref. [9], with reference to the pushover analysis. It was shown that some parameters (meeting the American detailing rules in the SAP default hinge model), such as the plastic hinge length and the transverse reinforcement spacing, may play a significant role on the displacement capacity of $\mathrm{r} / \mathrm{c}$ frames and, therefore, the adoption of user-defined plastic hinges is generally preferable to catch the building non-linear behaviour [9].

It can be observed that EC 8 does not suggest any specific plastic-hinge model to be implemented in the finite element analysis. To evaluate the impact of the choice of the plastic-hinge model on the results of the code-based NLTHA, both a Default-Hinge (DH) model, as assigned by SAP2000, and a User-Hinge (UH) model, based on the Dolšek-Fajfar momentrotation relationship [10], were considered. The moment-curvature diagrams of the two models, simplified as required by SAP2000, are given in Fig. 4. The values to be assigned to 


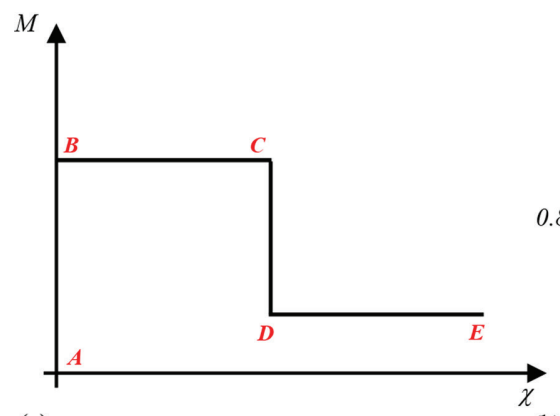

(a)

(b)

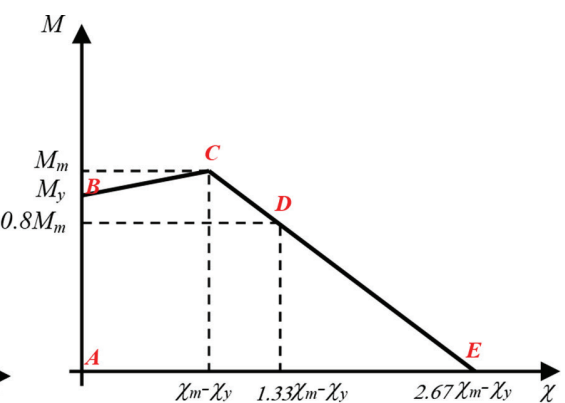

Figure 4: Moment-curvature diagram of (a) Default-Hinge and (b) User-Hinge.

points B, C, D and E vary depending on type of element, kind of materials, longitudinal steel percent and axial load level. They were automatically assigned for the DH, while a complete moment-curvature analysis was needed for the $\mathrm{UH}$, involving also a preliminary evaluation of axial loads in columns (due to dead loads and $30 \%$ of live loads). This step required the use of an external application and a significant expenditure of time to compute the large amount of hysteretic relationships (as also evidenced in Ref. [5]).

A kinematic hardening hysteretic model for unloading was implemented for the considered both models. According to EC8, the plastic hinge length should be at least:

$$
\begin{array}{ll}
\text { beams } & l_{c r B}=h_{b} \\
\text { columns } & l_{c r C}=\max \left\{h_{c} ; l_{c l} / 6 ; 0.45\right\} \quad \text { [in metres], }
\end{array}
$$

where $h_{b}$ and $h_{c}$ are the section height of beams and columns, while $l_{c l}$ is the column clear length. Cautiously, $l_{c r B}=1.5 h_{b}=0.675 \mathrm{~m}$ and $l_{c r C}=l_{c l} / 6=0.50 \mathrm{~m}$ was assumed for both models, also in accordance with the Italian code [7]. Note, that the DH elements needed to be converted into user-editable to allow modifying length and unloading law.

A Rayleigh classic damping was supposed. The damping matrix was thus obtained as a linear combination between the mass and the stiffness matrixes:

$$
[d]=a[m]+b[k] .
$$

The damping factor of the jth mode can be expressed, in this case, as:

$$
\xi_{j}=\frac{1}{2}\left(\frac{a}{\omega_{j}}+b \omega_{j}\right) .
$$

A constant value $\xi_{j}=\xi=0.05$ was assumed for each mode. The values of the coefficients appearing in eqn (2) in this case are then $\mathrm{a}=1.2526 \mathrm{~s}^{-1}$ and $\mathrm{b}=1.995 \mathrm{E}-3 \mathrm{~s}$.

\subsection{Step 3: setting the parameters for the numerical analysis with SAP2000}

Before starting a transient analysis some parameters should be set in SAP2000. After assigning the initial conditions under gravitational loads, the time step and the number of steps has to be chosen. Of course, shorting the time step generally leads to much precise results but it can also highly increase the computing effort. 
(a)

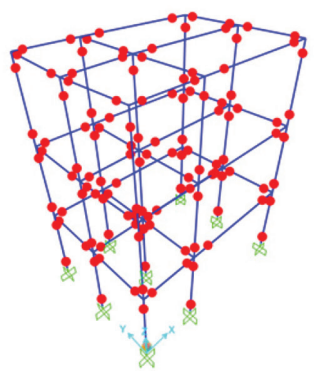

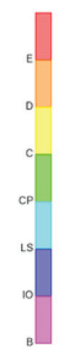

(b)

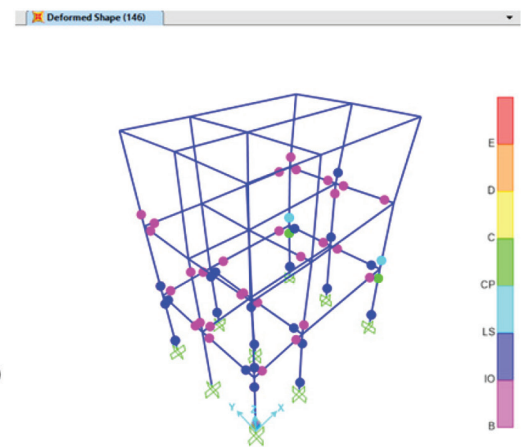

Figure 5: Deformation envelope for (a) $\alpha=0$ and (b) $\alpha=-0.2$ (waveform 146 of Suite 1; UH model).

The Hilber-Hughes-Taylor (HHT) method (also known as alpha method) [11] is adopted by default by SAP2000 for the direct integration of the motion equations. Based on the Newmark formulation, it defines the two parameters $\beta$ and $\gamma$ as a function of a single parameter $\alpha$ :

$$
\beta=\frac{(1-\alpha)^{2}}{4}, \gamma=\frac{1}{2}-\alpha
$$

The range of practical interest for $\alpha$ is $-1 / 3 \leq \alpha \leq 0$, [11]. For $\alpha=0$ the method coincides with the Newmark formulation. On the other hand, values of $\alpha$ lower than zero (negative) may facilitate the convergence of the solution by reducing the contribution of the higher modes, which acts as a sort of numerical dissipation. However, this may affect the accuracy of the final results, as the instances provided by Fig. 5 put in evidence.

To avoid such an accuracy problem, $\alpha=0$ was initially set for every transient analysis of the present investigation. However, this value being set, a significant number of analyses, typically the ones relevant to the strongest events of each suite, failed the convergence. This required lowering the value of $\alpha$ till the convergence was reached. In many of the considered cases, the convergence occurred only when the limit value $\alpha=-1 / 3$ was chosen. In some other cases this was not enough, thus leading to some considerations about the violence of the suites of earthquakes considered and about the ductile resources of the building, as discussed in the following section.

\section{CONVERGENCE PROBLEMS AND EXTRA DUCTILITY DEMAND}

A great amount of non-linear analyses were performed, by considering the earthquakes of the four suites of Table 1, the two plastic hinge models and different values of the integration parameters. The solution failed in several cases, particularly when the earthquakes of Suite 1 and Suite 3 were involved. Although matching in average the same tolerance bounds, the earthquakes of Suite 1 (or of Suite 3) are in fact stronger than those of Suite 2 (or Suite 4). In addition, for each given earthquake, the success or failure of the solution depended also on the plastic-hinge model and on the HHT alpha parameter.

Setting the lowest admissible value $\alpha=-0.33$ leaded to solve most of the convergence problems, but in some cases, this was not enough. For instance, under the 6263 earthquake of 
Table 4: Solution convergence map ( $\mathrm{Y}=$ success; $\mathrm{N}=$ failure).

\begin{tabular}{|c|c|c|c|c|c|c|c|c|c|c|c|c|c|c|}
\hline $\begin{array}{l}\text { SUITE } 1 \\
\text { waveform }\end{array}$ & & & & 99 & & 30 & 2 & 91 & & 15 & & 63 & & 334 \\
\hline & UH & $\mathrm{DH}$ & UH & $\mathrm{DH}$ & UH & $\mathrm{DH}$ & UH & $\mathrm{DH}$ & $\mathrm{UH}$ & $\mathrm{DH}$ & $\mathrm{UH}$ & $\mathrm{DH}$ & $\mathrm{UH}$ & $\mathrm{DH}$ \\
\hline 0 & $\mathrm{Y}$ & $Y$ & $\mathbf{N}$ & $\mathrm{Y}$ & Y & $\mathrm{Y}$ & $\mathrm{Y}$ & $\mathrm{Y}$ & $\mathbf{N}$ & $\mathrm{Y}$ & $\mathbf{N}$ & $\mathbf{N}$ & $\mathbf{N}$ & $\mathrm{Y}$ \\
\hline-0.33 & $\mathrm{Y}$ & $\mathrm{Y}$ & $\mathbf{N}$ & $\mathrm{Y}$ & $\mathrm{Y}$ & $\mathrm{Y}$ & $\mathrm{Y}$ & $\mathrm{Y}$ & $\mathrm{Y}$ & $\mathrm{Y}$ & $\mathbf{N}$ & $\mathbf{N}$ & $\mathbf{N}$ & $\mathrm{Y}$ \\
\hline $\begin{array}{l}\text { SUITE } 2 \\
\text { waveform }\end{array}$ & & & & 32 & & 91 & 5. & 35 & & 94 & & 11 & 17 & 713 \\
\hline & UH & $\mathrm{DH}$ & $\mathrm{UH}$ & $\mathrm{DH}$ & $\mathrm{UH}$ & $\mathrm{DH}$ & UH & $\mathrm{DH}$ & $\mathrm{UH}$ & $\mathrm{DH}$ & $\mathrm{UH}$ & $\mathrm{DH}$ & $\mathrm{UH}$ & $\mathrm{DH}$ \\
\hline $\begin{array}{l}\alpha \\
0\end{array}$ & $Y$ & $Y$ & $\mathbf{N}$ & $\mathrm{Y}$ & $\mathbf{N}$ & $Y$ & $Y$ & $\mathrm{Y}$ & $\mathrm{Y}$ & $Y$ & $\mathbf{N}$ & $Y$ & $\mathbf{N}$ & $Y$ \\
\hline-0.33 & $\mathrm{Y}$ & $\mathrm{Y}$ & $\mathrm{Y}$ & $\mathrm{Y}$ & $\mathrm{Y}$ & $\mathrm{Y}$ & $\mathrm{Y}$ & $\mathrm{Y}$ & $\mathrm{Y}$ & $\mathrm{Y}$ & Y & $\mathrm{Y}$ & $\mathrm{Y}$ & $\mathrm{Y}$ \\
\hline $\begin{array}{l}\text { SUITE } 3 \\
\text { waveform }\end{array}$ & & & & 91 & & 14 & 46 & 73 & & 28 & & 99 & & 35 \\
\hline & UH & $\mathrm{DH}$ & UH & $\mathrm{DH}$ & UH & $\mathrm{DH}$ & $\mathrm{UH}$ & $\mathrm{DH}$ & UH & $\mathrm{DH}$ & UH & $\mathrm{DH}$ & UH & $\mathrm{DH}$ \\
\hline$\alpha$ & & & & & & & & & & & & & & \\
\hline 0 & $\mathrm{Y}$ & $\mathrm{Y}$ & $\mathrm{Y}$ & $\mathrm{Y}$ & $\mathrm{Y}$ & $\mathrm{Y}$ & $\mathbf{N}$ & $\mathbf{N}$ & $\mathbf{N}$ & $\mathbf{N}$ & $\mathbf{N}$ & $\mathbf{N}$ & $\mathbf{N}$ & $\mathbf{N}$ \\
\hline-0.33 & Y & Y & $\mathrm{Y}$ & $\mathrm{Y}$ & $\mathrm{Y}$ & $\mathrm{Y}$ & $\mathbf{N}$ & $\mathbf{N}$ & $\mathbf{N}$ & $\mathbf{N}$ & $\mathbf{N}$ & $\mathrm{Y}$ & $\mathbf{N}$ & $\mathrm{N}$ \\
\hline $\begin{array}{l}\text { SUITE } 4 \\
\text { waveform }\end{array}$ & & & & 47 & & 63 & 1. & 46 & & 35 & & 30 & & 91 \\
\hline & $\mathrm{UH}$ & $\mathrm{DH}$ & UH & $\mathrm{DH}$ & $\mathrm{UH}$ & $\mathrm{DH}$ & $\mathrm{UH}$ & $\mathrm{DH}$ & $\mathrm{UH}$ & $\mathrm{DH}$ & $\mathrm{UH}$ & $\mathrm{DH}$ & $\mathrm{UH}$ & $\mathrm{DH}$ \\
\hline$\alpha$ & & & & & & & & & & & & & & \\
\hline 0 & $\mathbf{N}$ & $\mathrm{Y}$ & $\mathrm{Y}$ & $\mathrm{Y}$ & $\mathbf{N}$ & $\mathbf{N}$ & $\mathrm{Y}$ & $\mathrm{Y}$ & $\mathbf{N}$ & $\mathrm{Y}$ & Y & $Y$ & $\mathbf{N}$ & $\mathrm{Y}$ \\
\hline-0.33 & $\mathrm{Y}$ & $\mathrm{Y}$ & $\mathrm{Y}$ & $\mathrm{Y}$ & $\mathrm{Y}$ & $\mathrm{Y}$ & $\mathrm{Y}$ & $\mathrm{Y}$ & $\mathrm{Y}$ & $\mathrm{Y}$ & $\mathrm{Y}$ & $\mathrm{Y}$ & $\mathrm{Y}$ & $\mathrm{Y}$ \\
\hline
\end{tabular}

Suite 1 the convergence was never reached for both the plastic hinge models, see Table 4 . Although spectrum-compatible for EC8 criteria, the 6263 earthquake has a response spectrum even five times higher than the target elastic spectrum, see Fig. 3a. Some numerical tests indicated that the convergence problems were due to the excessive violence of the earthquake with respect to the building design features, which implied a ductility demand greater than was available. As an example, Figs $6 a$ and $b$ show that the 6263 y-acceleration should be scaled by a factor 0.2 to lead the solution to converge (even if all the plastic hinges in the UH model reached the maximum curvature). Conversely, to reach the convergence under the original 6263 earthquake, the ductility capacity should be increased tenfold in both the UH and DH models. Figures $6 \mathrm{c}$ and $6 \mathrm{~d}$ plot the $\mathrm{x}$ and $\mathrm{y}$ dispacements of the first floor target point as obtained by increasing tenfold the ultimate curvature of all end sections. Note, however, that the two plastic-hinge models behave differently under the same earthquake. Larger displacements are in fact, demanded to the UH model in both directions. 


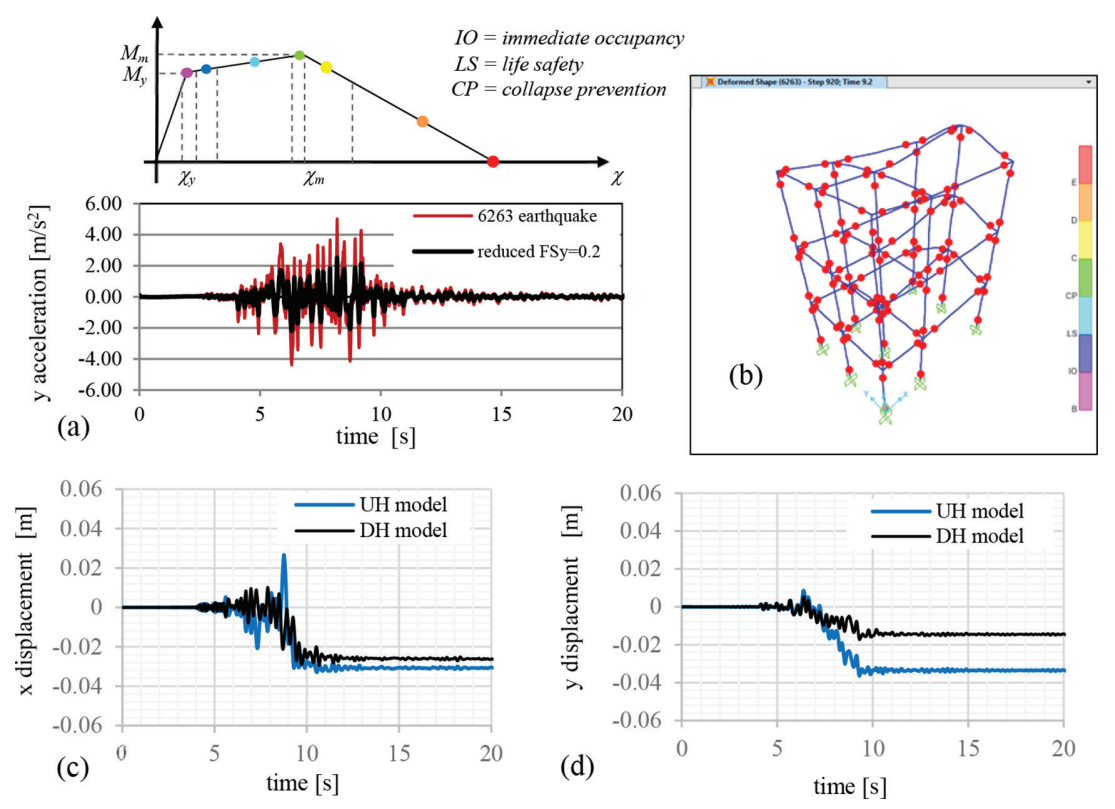

Figure 6: (a) Original and reduced 6263 y-acceleration; (b) deformed shape under the reduced earthquake; (c-d) $\mathrm{x}$ and $\mathrm{y}$ displacements of the first-floor target point under the original 6263 earthquake, as obtained by increasing tenfold the ductility of end sections.

To obtain the solution convergence under any earthquake of the considered suites, the ductility capacity of the plastic hinges was fictitiously increased every time it was necessary (this required, of course, a very lengthy user job). An extra ductility demand ranging from two times (record 535 of Suite 3) to ten times (record 6263 of Suite 1) the capacity was found for the earthquakes that caused convergence problems. Moreover, to compare homogeneous results, $\alpha=-0.33$ was set for all the events and for both plastic-hinge models. A comparison between the averaged y-displacements at storey levels, as obtained from the NLTHA and from the MRSA, is given in Fig. 7. The diagrams show that when scaled records are taken into account (Suites 2 and 4), the MRSA gives, as expected, more conservative results than the NLTHA. On the contrary, as far as original records are taken into account (Suites 1 and 3), the MRSA may be less conservative. In particular, the averaged displacements of the UH model may greatly exceed those of the MRSA. This result contrasts with the fact that, being more simpler (and less reliable) the MRSA should be more conservative than the NLTHA (similar concerns are discussed in Ref. [12]). It is to note that the response of the two plastic-hinge models is very similar under less violent events (Suites 2 and 4), while it may largely differ under stronger earthquakes (Suites 1 and 3).

\section{CONCLUDING REMARKS}

Although meeting all the ductility and strength hierarchy rules given by EC8, reinforced concrete frames designed through a code-compliant linear analysis (MRSA), may be unable to resist earthquakes that EC8 considers compatible with the design response spectrum. The present investigation showed in fact that some of such earthquakes are so strong that the ductility demand they involve can be even ten times the building capacity. Such an inconsistency 

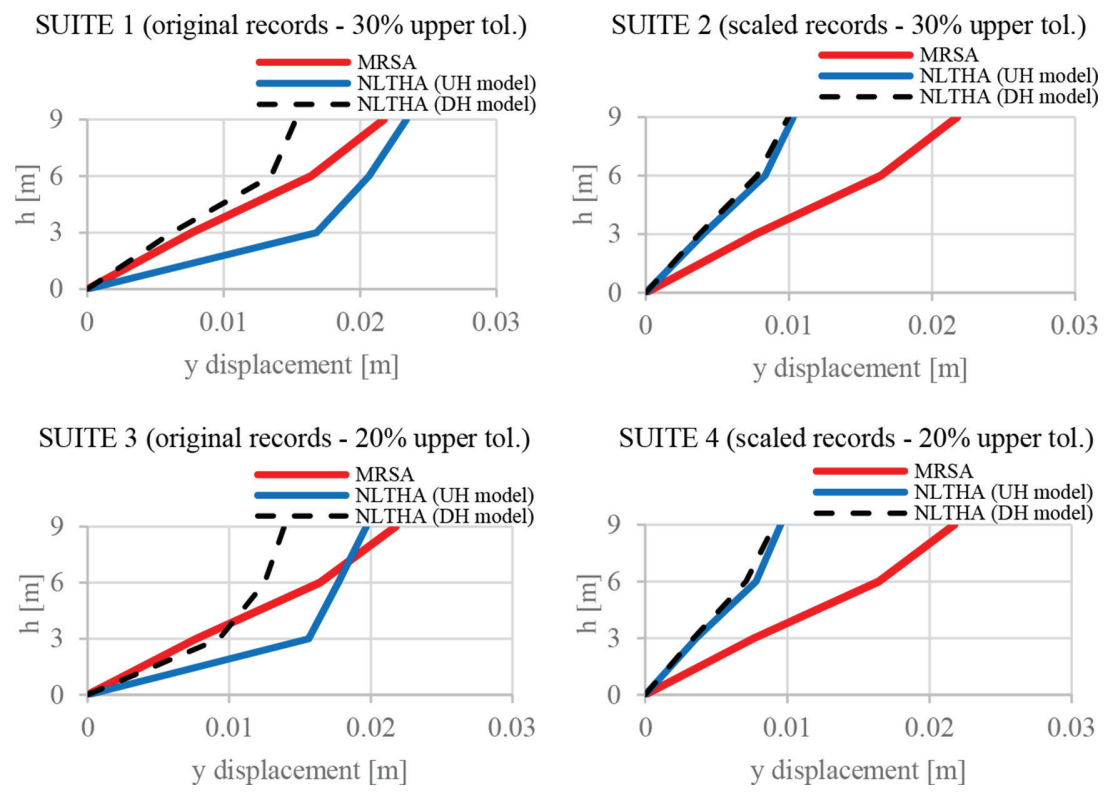

Figure 7: Comparison of the averaged y-displacements of the floors of the building obtained from the NLTHA and the MRSA.

is mainly due to the lack (in the EC8 provisions) of an upper tolerance bound for the average spectrum of the suite of compatible earthquakes. Setting an upper limit of $30 \%$ or even only of $20 \%$ may lead to convergence problems, at least under the strongest records of the suite. On the other hand, refer to a suite of earthquakes scaled to meet the upper tolerance bound, may significantly increase the chances of success of the analysis than to refer to original records. In addition, the paper showed that adopting the default hinge model given by SAP (based on the American codes) might lead to underestimate the actual ductility demand. However, assuming a more suitable user-defined hinge model requires a large amount of preliminary work, involving also the use of external applications to obtain the moment-curvature relationship for each critical section. In any case, no indications are given by EC 8 on which plastic hinge model is better to adopt. Such difficulties can discourage the designer by using the more accurate non-linear dynamic analysis for seismic design. Some revisions of the EC8 provisions might help to avoid the inconsistencies evidenced by the present investigation.

\section{AKNOWLEDGEMENTS}

The author gratefully acknowledges Eng. Dario Cannaos and Eng. Peiman Novin for the numerical simulations made during their master's thesis.

\section{REFERENCES}

[1] FEMA-356, Prestandard Commentary for the Seismic Rehabilitation of Buildings. Federal Emergency Management Agency, Washington, DC, 2000.

[2] ATC-40, Seismic evaluation and retrofit of concrete buildings. Applied Technology Council, report ATC-40. Redwood City, 1996. 
[3] CSI, SAP2000 v.17. Integrated Finite Element Analysis and Design of Structures Basic Analysis Reference Manual. Computers and Structures, Inc., Berkeley, California, USA, 2014.

[4] Iervolino, I., Galasso, C. \& Cosenza, E., REXEL: computer aided record selection for code-based seismic structural analysis. Bulletin of Earthquake Engineering, 8(2), pp. 339-362, 2010. https://doi.org/10.1007/s10518-009-9146-1

[5] Carvalho, G., Bento, R. \& Bhatt, C., Nonlinear static and dynamic analyses of reinforced concrete buildings-comparison of different modelling approaches. Earthquake and Structures, 4(5), pp. 451-470, 2013. https://doi.org/10.12989/eas.2013.4.5.451

[6] CEN. Eurocode 8: Design of Structures for Earthquake Resistance - Part 1: General Rules, Seismic Actions and Rules for Buildings. European Comitee for Standardization, Brussels, p. 232., 2004.

[7] NTC 2008, Norme tecniche per il calcolo, l'esecuzione ed il collaudo delle strutture in cemento armato, normale e precompresso e per le strutture metalliche. In Italian, 2008.

[8] Ambraseys, N., Smit, P., Douglas, J., Margaris, B., Sigbjörnsson, R., Olafsson, S., Suhadolc, P. \& Costa, G., Internet site for European strong-motion data. Bollettino di Geofisica Teorica ed Applicata, 45(3), pp. 113-129, 2004.

[9] Inel, M. \& Ozmen, H.B., Effects of plastic hinge properties in nonlinear analysis of reinforced concrete buildings. Engineering Structures, 28(11), pp. 1494-1502, 2006. https://doi.org/10.1016/j.engstruct.2006.01.017

[10] Dolšek, M. \& Fajfar, P., The effect of masonry infills on the seismic response of a fourstorey reinforced concrete frame-a deterministic assessment. Engineering Structures, 30(7), pp. 1991-2001, 2008.

https://doi.org/10.1016/j.engstruct.2008.01.001

[11] Hilber, H.M., Hughes, T.J.R. \& Taylor, R.L., Improved numerical dissipation for time integration algorithms in structural dynamics. Earthquake Engineering and Structural Dynamics, 5, pp. 283-292, 1977. https://doi.org/10.1002/eqe.4290050306

[12] Paglietti, A., Porcu, M.C. \& Pittaluga, M., A loophole in the Eurocode 8 allowing for non-conservative seismic design. Engineering Structures, 33, pp. 780-785, 2011. https://doi.org/10.1016/j.engstruct.2010.12.001 